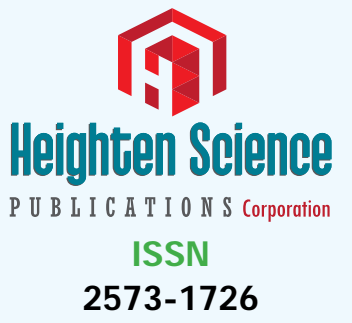

*Address for Correspondence: Dr. Giovane Galdino, School of Physical Therapy, Jovino Fernandes Sales Ave. 2600, Santa Clara, Alfenas, Minas Gerais, Brazil, Tel: 005135-37011923. Email: giovanegsouza@yahoo.com.br

Submitted: 10 April 2017

Approved: 1 May 2017

Published: 02 May 2017

Copyright: @ 2017 Borges JBC, et al. This is an open access article distributed under the Creative Commons Attribution License, which permits unrestricted use, distribution, and reproduction in any medium, provided the original work is properly cited.

Keywords: Cardiovascular rehabilitation Hypertension; Aerobic exercise
Research Article

\section{Effects of a short Cardiovascular Rehabilitation program in Hypertensive subjects: A Pilot Study}

\author{
J uliana Bassalobre Carvalho Borges, Débora Tazinaffo Bueno, \\ Monique Fernandes Peres, Ana Paula Aparecida Mantuani, \\ Andréia Maria Silva and Giovane Galdino*
}

Physical Therapy School, Federal University of Alfenas, Alfenas, Minas Gerais, Brazil

\section{ABSTRACT}

Systemic arterial hypertension (SAH) is considered an important risk factor for the development of cardiovascular diseases. The aim of the present study was to verify the effects of a short cardiovascular rehabilitation program (CR) in hypertensive subjects. The clinical pilot study involved a sample composed of 11 hypertensive subjects. It was evaluated the weight, height, body mass index (BMI), waist and hip circumference, waist hip ratio, systolic blood pressure (SBP), diastolic blood pressure (DBP) and six-minute walk test (6-MWT) before and after CR. CR was performed twice a week for 60 minutes. The results shown that after CR occurred a reduction of waist circumference $(99.86 \pm 8.7$ to $95.2 \pm 8.6 \mathrm{~cm}, \mathrm{p}=0.0002)$ and hip circumference $(110.18 \pm 14.75$ to $105.00 \pm 12.7 \mathrm{~cm} \mathrm{p}=0.01)$ values. About the mean distance walked in the 6-MWT there was an increase after the $\mathrm{CR}$ program $(335.9 \pm 123.5 \mathrm{~m}$ to $554.56 \pm 87.9 \mathrm{~m}, \mathrm{p}=0.000)$. In conclusion, the results suggest that a short $\mathrm{CR}$ is an effective for the treatment of hypertensive subjects. After $16 \mathrm{CR}$ sessions, functional and musculoskeletal capacity was improved, evaluated by 6-MWT. Furthermore, the short CR program decreased waist and hip circumferences, being an important option for these subjects. Although. There were no changes in baseline blood pressure levels.

\section{INTRODUCTION}

Cardiovascular diseases are leading the causes of death in the world [1]. Among these diseases, systemic arterial hypertension ( $\mathrm{SAH}$ ) is considered an important risk factor for the development of cardiovascular diseases. SAH is a multifactorial disease characterized by high and sustained levels of blood pressure (BP) [2]. Epidemiological studies have revealed an association between low level of physical activity and the presence of hypertension. Furthermore, randomized clinical trials and meta-analyzes have confirmed that regular exercise can reduce blood pressure levels, improve quality of life, and interfere positively in the cardiovascular risk factors [3].

Cardiovascular rehabilitation programs (CR) consist of an individualized approach of patients with global goals that aim at reducing cardiovascular risk and improving quality of life. This approach should be carried out by the multi-professional team with emphasis on controlling risk factors, reducing physical disabilities and adopting healthy behaviors such as active lifestyle [4]. The physiotherapeutic approach in cardiovascular rehabilitation is preventive in the intervention on the precipitating and aggravating factors of cardiovascular diseases (risk factors) and curative, in the rehabilitation of cardiovascular, respiratory, metabolic, humoral and muscular functions (after the event of established heart disease, infarction acute myocardial infarction and cardiac surgery) [5].

Most studies that have investigated the effect of CR in hypertensive subjects, which are performed in chronic programs and, thus the present study aimed evaluate the effect of a short CR program in this disease. 


\section{MATERIAL AND METHODS}

\section{Participants}

The present study is a clinical pilot study, quantitative and descriptive study with hypertensive individuals carried out for treatment in the Cardiovascular Physiotherapy sector, at the Physiotherapy Clinic of the Federal University of Alfenas (UNIFAL). The sample consisted of 11 patients of both sexes (male=4 and female=7) mean age $57.09 \pm 10.95$ years with arterial hypertension and two with diabetes association. All individuals signed the informed consent form. The inclusion criteria were the following: sedentary participants and have no history of psychiatry or psychological disorders, aged $\geq 30$ years with chronic mild-to-moderate and stable ( $>1$ year duration) hypertension. Subjects excluded from the study included those with grade III or IV heart failure, recent acute myocardial infarction, unstable angina, acute pericarditis, pulmonary hypertension or severe untreated blood pressure (SBP $\geq 200 \mathrm{mmHg}$ and $\mathrm{DBP} \geq 110 \mathrm{mmHg}$ ), ventricular tachycardia at rest, acute infections, III or IV peripheral arterial obstruction, uncontrolled diabetes and those subjects who did not complete 16 CR sessions and who refused.

All participants present the controlled blood pressure values, which take medicines for hypertension, including beta-blockers and diuretics.

Interview and anthropometric measurement

Firstly, all subjects were underwent to interview with a physiotherapist. The interview evaluated the time of hypertension onset, symptoms, life quality, pharmacotherapy, physical activity, and work. In addition, an anthropometric measurement was performed, which measured the subjects' physical characteristics (weight [kg] and height[m]), body composition (body mass index [BMI] (kg/m2), waist and hip circumference [6]. The BMI was evaluated by means of the calculation between body mass in kg, divided by height in meters squared. The categories of Body Mass Index (BMI) were adopted, based on the reference values by the WHO: underweight ( $<18.5 \mathrm{~kg} / \mathrm{m}^{2}$ ); eutrophic (18.5 to $24.9 \mathrm{~kg} / \mathrm{m}^{2}$ ); overweight (25 to $29.9 \mathrm{~kg} / \mathrm{m}^{2}$ ), and obese ( $\geq 30 \mathrm{~kg} / \mathrm{m}^{2}$ ) [6]. Furthermore, six minute walk test (6-MWT) was used to evaluate the cardiovascular and physical conditioning. The 6MWT was performed according to ATS standards at 30-min intervals [7]. The participants were instructed to walk as far as possible for $6 \mathrm{~min}$ in a $30-\mathrm{m}$ hallway and were given standardized verbal encouragement every minute. 6-MWT were recorded in meters and as a percentage of reference values for further analysis [8]. Before and after the test, heart rate (HR), respiratory rate (RF), systolic and diastolic blood pressure (SBP and DBP), peripheral oxygen saturation (Sp02) and the rate of perceived exertion (dyspnea and leg fatigue) evaluated by Borg scale, were measured [9].

\section{Cardiac rehabilitation program}

In the short CR program, the patients underwent to aerobic exercise on a treadmill (Movement RT250- Manaus, AM, Brazil), 2 times a week for 8 weeks. Exercise sessions started with a 10-minute warm-up period (stretching and slow walking) followed by 30 minutes of aerobic activity on a treadmill and ended with an appropriate cooling-off period of 10 minutes [10]. Patients exercised at 60 to $70 \% \mathrm{HR}$, calculated according to the Karvonen formula, which was measured continuously with a portable HR monitor (Polar RS200, Woodbury, NY, USA). In addition, blood pressure was monitored periodically during each workout. After CR program were did a new anthropometric measurement and 6-MWT.

Statistical analysis

Descriptive data were expressed as mean and standard deviation. Data normality was verified through the KolmogorovSmirnov test. For comparison between the 
intragroup evaluations, the paired t-test and the Wilcoxon test. To comparison intergroup, was used t-test independent, Mann-Whitney and one-way ANOVA. A Significance level of 5\% was adopted. Statistical analyses were performed using SPSS for Windows version 20.0 (SPSS, Chicago, IL, USA).

\section{RESULTS}

The results of table 1 shown that a short CR program significantly reduced of waist circumference $(99.86 \pm 8.7$ to $95.2 \pm 8.6 \mathrm{~cm}, \mathrm{p}=0.0002)$ and hip circumference $(110.18 \pm 14.75$ to $105.00 \pm 12.7 \mathrm{~cm} \mathrm{p}=0.01)$ values. However, although occurred these reductions, the weigh and BMI have not been changed (Table 1 ).

In addition, the SBP $(124.55 \pm 11.2$ to $123.18 \pm 9.02, \mathrm{p}=0.7)$ and DPB $(80.0 \pm 15.49$ to $78.18 \pm 10.78, \mathrm{p}=0.6$ ) levels also have not been changed after the CR program (Figure $1)$.

Concerning 6-MWT, after the CR program the subjects significantly increased the walking distance (335.99 \pm 123.5 to $554.56 \mathrm{~m} \pm 87.9, \mathrm{p}=0,000)$ (Figure 2).

Table 1: anthropometric measurement performed before and after a short cardiac rehabilitation program.

\begin{tabular}{|c|c|c|}
\hline anthropometric measurement & Before CR & After CR \\
\hline $\mathrm{WC}(\mathrm{cm})^{\star}$ & $99.86 \pm 8.79$ & $95.27 \pm 8.64$ \\
\hline $\mathrm{HC}(\mathrm{cm})^{\star}$ & $110.18 \pm 14.75$ & $105.0 \pm 12.79$ \\
\hline weight $(\mathrm{Kg})$ & $82.1 \pm 14.6$ & $81.2 \pm 13.13$ \\
\hline height $(\mathrm{m})$ & $1.60 \pm 7.07$ & $1.60 \pm 7.07$ \\
\hline $\mathrm{BMI}\left(\mathrm{Kg} / \mathrm{m}^{2}\right)$ & $32.17 \pm 6.60$ & $31.39 \pm 5.95$ \\
\hline
\end{tabular}

CR: Cardiac Rehabilitation Program; WC: waist circuference; HC: hip circuference; BMI: body mass index. $p<0.05$

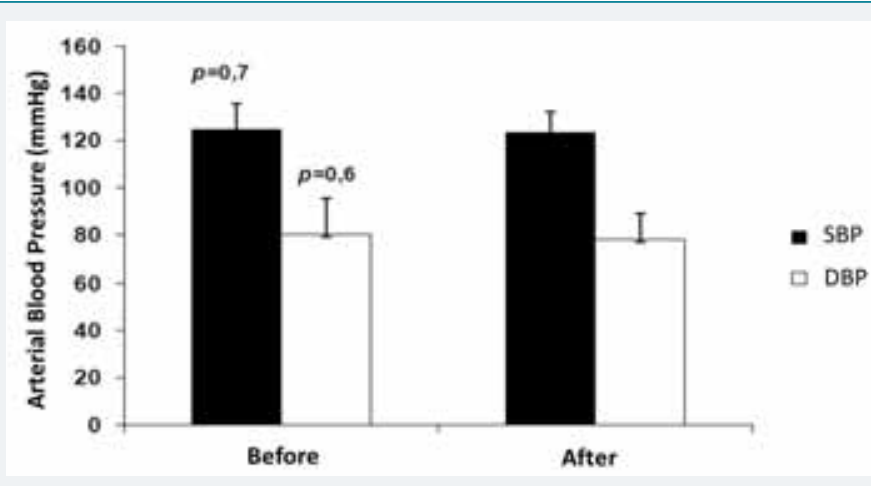

Figure 1: Effect of a short cardiac rehabilitation (CR) program on the arterial blood pressure levels. The systolic blood pressure (SBP) and diastolic blood pressure values (DBP) were not changed ( $p>0.7$ and $p>0.6$, respectively) after CR program. 


\section{DISCUSSION}

The present study shows that a short period of cardiac rehabilitation program was effective in increasing both cardiorespiratory and muscular conditioning, as can be seen in the significant results that found reduction in the waist and hip circumferences and the increase in the walking distance in the 6MWT. A study demonstrated that both circumferences are strong indicators of hypertension risk [11] and, the present study shown that physical exercise performed in a short training period may to reduce this risk. Supporting, a study concluded that both regular physical activity and a normal weight can reduce the risk of cardiovascular diseases and, the physical inactivity seems to have an independent effect on cardiovascular diseases risk, whereas obesity increases the risk partly through the modification of other risk factors [12]. However, most studies have found these beneficial effect using chronic exercise training and, the present study suggest that these risk may be reduced with a short period of exercise.

In addition, it was demonstrated by the 6-MWT that after short CR program, participants could walk a greater distance, demonstrating a gain in physical and cardiovascular conditioning through the exercise protocol used. 6-MWT is commonly used to assess the fitness level of healthy adults and of older adults with disabilities and pathologies, such as stroke, chronic obstructive pulmonary disease, pulmonary arterial hypertension, pulmonary fibrosis, and heart failure [13-15]. However, studies evaluating the 6-MWT in hypertensive subjects are rare. The 6-MWT is highly reproducible and is a strong marker of prognosis of several treatments.

Statistically non-significant BMI and weight values were found, suggesting that perhaps the nutritional approach in this case may also be important, since a cardiac rehabilitation program should provide patients with health education actions for a necessary and real change in life habits; therefore it is essential that a CR program has a multidisciplinary team. The introduction of diets in this type of program plays a key role in the ischemic heart disease control, since the ingestion of foods rich in saturated fat, calories and salt can result in the development of dyslipidemias, obesity, diabetes mellitus and hypertension $[16,17]$. In addition, a study found that training without dietary modification in obese people does not seem to be sufficient to produce a significant loss of fat body mass and the an important strategy is to associate physical exercise with diet [18]. The American Heart Association also recommends maintaining healthy weight, aided by regular physical activity and moderate fat consumption $(<30 \%)[19]$.

It is known that lifestyle modifications, including diet and exercise, are the first lines of intervention for high BP control, even when drug therapy is implemented [20].

Most studies have shown that physical activity may reduce high levels of arterial blood pressure in hypertensive subjects [21]. However, in the present study this reduction did not found. We suggesting that to occurs a reduction in the blood pressure values the training period should be greater than 16 sessions ( 2 months). Furthermore, same participants had the levels controlled. Studies have demonstrated that the reduction in the arterial blood pressure levels of hypertensive subjects were found only after 9 months of aerobic training [22-24].

\section{CONCLUSIONS}

The results of present study suggest that the proposed short period of CR program was effective for the treatment of hypertensive subjects. After 16 sessions, functional and musculoskeletal capacity was improved, evaluated by 6-MWT and waist and hip circumferences decreased, being a good strategy therapeutic for these subjects. The results did not find change in baseline SBP and DBP levels, showing that a CR program should cover much more than physical training, providing patients with health 
education for a real change in lifestyle, emphasizing the nutritional habits that are of extreme importance to help reduce BMI, weight and consequently cardiovascular risk factors. Another advantage of proposed program is the adherence of participants. A problem of CR programs is the adherence, mainly because of high costs, distance etc. and, in the present study there was no quitting. Thus, this study presents ongoing seeking to expand the sample and confirm the positive effects of a short period of CR program in hypertensive individuals.

\section{ACKNOWLEDGMENTS}

We would like to thank all the participants that took part in the study and to Luiz Tomáz by technical support.

\section{REFERENCES}

1. World Health Organization (WHO). Obesity: preventing and managing the global epidemic. Report of a WHO consultation. World Health Organ Tech Rep Ser. 2000; 894: 1-11. Ref.: https://goo.gl/Od6T8T

2. Sociedade Brasileira de Cardiologia/Sociedade Brasileira de Hipertensão/Sociedade Brasileira de Nefrologia. VI Diretrizes Brasileiras de Hipertensão. Arq Bras Cardiol. 2010; 95: 1-51 Ref.:

3. Diaz KM, Shimbo D. Physical Activity and the Prevention of Hypertension. Curr Hypertens Rep. 2013; 15: 659-668. Ref.: https://goo.gl/LHRt7c

4. Pescatello LS, Franklin BA, Fagard R, Farquhar WB, Kelley GA, et al. American College of Sports Medicine. American College of Sports Medicine position stand. Exercise and hypertension. Med Sci Sports Exerc. 2004; 36: 533-553. Ref.: https://goo.gl/KgsCkW

5. Mampuya WM. Cardiac rehabilitation past, present and future: an overview. Cardiovasc Diagn Ther. 2012; 2: 38-49. Ref.: https://goo.gl/o3FEuz

6. Institute of Medicine. National Research Council. Weight Gain during Pregnancy: Reexamining the Guidelines. Washington (DC). National Academy of Science. 2009.

7. ATS Committee on Proficiency Standards for Clinical Pulmonary Function Laboratories. ATS statement: guidelines for the six-minute walk test. Am J Respir Crit Care Med. 2002; 166: 111-117. Ref.: https://goo.gl/AHINpH

8. Dourado VZ, Vidotto MC, Guerra RL. Reference equations for the performance of healthy adults on field walking tests. J Bras Pneumol. 2011; 37: 607-614. Ref.: https://goo.gl/oqNaAm

9. Borg GA. Psychophysical bases of perceived exertion. Med Sci Sports Exerc. 1982; 14: 377-381. Ref.: https://goo.gl/zSK1Cz

10. 7th ed. Philadelphia: Lippincott. Williams and Wilkines. American College Of Sports Medicine (ACSM)-Guidelines for exercise testing and prescription. 2006.

11. Feldstein CA, Akopian M, Olivieri AO, Kramer AP, Nasi M, et al. A comparison of body mass index and waist-to-hip ratio as indicators of hypertension risk in an urban Argentine population: a hospitalbased study. Nutr Metab Cardiovasc Dis. 2005; 15: 310-315. Ref.: https://goo.gl/ma3zqM

12. Hu G, Tuomilehto J, Silventoinen K, Barengo N, Jousilahti P. Joint effects of physical activity, body mass index, waist circumference and waist-to-hip ratio with the risk of cardiovascular disease among middle-aged Finnish men and women. Eur Heart J. 2004; 25: 2212-2219. Ref.: https://goo.gl/PmJ1UJ

13. Rubin LJ. The 6-minute walk test in pulmonary arterial hypertension: how far is enough? Am J Respir Crit Care Med. 2012; 186: 396-397. Ref.: https://goo.gl/SSNGzn

14. Swigris JJ, Olson AL, Shlobin OA, Brown KK, Nathan SD. Heart rate recovery after six-minute walk test predicts pulmonary hypertension in patients with idiopathic pulmonary fibrosis. Respirology. 2011; 16: 439-445. Ref.: https://goo.gl/gyNIAd

15. Demers C, McKelvie RS, Negassa A, Yusuf S, RESOLVD Pilot Study Investigators. Reliability, validity, and responsiveness of the six-minute walk test in patients with heart failure. Am Heart J. 2001; 142: 698-703. Ref.: https://goo.gl/BM0akE

16. Souza MFM, Timerman A, Serrano Jr CV, Santos RD, Mansur AP, et al. Tendência do risco de morte por doenças circulatórias no Brasil de1979 and 1996. Arq Bras Cardiol. 2001; 76: 497-510. Ref.: https://goo.gl/jUORhz 
17. Buttar HS, Li T, Ravi N. Prevention of cardiovascular diseases: Role of exercise, dietary interventions, obesity and smoking cessation. Exp Clin Cardiol. 2005; 10: 229-249. Ref.: https://goo.gl/6hr7ix

18. Grilo CM. Physical activity and obesity. Biomed Pharmacother. 1994; 48: 127-136. Ref.: https://goo.gl/QG0yu7

19. de Lorgeril M, Renaud S, Mamelle N, Salen P, Martin JL, et al. Mediterranean Alpha-Linolenic AcidRich Diet in Secondary Prevention of Coronary artery disease. Lancet. 1994; 343: 1454-1459. Ref.: https://goo.gl/OByvOB

20. Monteiro HL, Rolim LMC, Squinca DA, Silva FC, Ticianeli CC, et al. Efetividade de um programa de exercícios no condicionamento físico. perfil metabólico e pressão arterial de pacientes hipertensos. Ver Bras Med Esporte. 2007; 13: 107-112. Ref.: https://goo.gl/awaLZu

21. Diaz KM, Shimbo D. Physical activity and the prevention of hypertension. Curr Hypertens Rep. 2013; 15: 659-668. Ref.: https://goo.gl/9hxlSJ

22. Punia S, Kulandaivelan S, Singh V, Punia V. Effect of Aerobic Exercise Training on Blood Pressure in Indians: Systematic Review. Int J Chronic Dis. 2016; 2016: 1370148. Ref.: https://goo.gl/4KX3ZS

23. Mughal MA, Alvi IA, Akhund IA, Ansari AK. The effects of aerobic exercise training on resting blood pressure in hypertensive patients. J Pak Med Assoc. 2001; 51: 222-226. Ref.: https://goo.gl/0yUrVK

24. Sousa N, Mendes R, Abrantes C, Sampaio J, Oliveira J. A randomized 9-month study of blood pressure and body fat responses to aerobic training versus combined aerobic and resistance training in older men. Exp Gerontol. 2013; 48: 727-733. Ref.: https://goo.gl/Ms5GiD 